\title{
The possibility of dietary protective factors in duodenal ulcer
}

\author{
F. I. TOVEY* \\ Ch.M., F.R.C.S. \\ A. Paul Jayaraj \\ M.Phil., M.I.Biol. \\ C. G. Clark \\ M.D., Ch.M., F.R.C.S. \\ Department of Surgery, University College Hospital Medical School, London
}

\begin{abstract}
Summary
Rats fed on a supplement of raw cabbage, brinjal, dhal or powdered milk given in addition to a staple rice or laboratory stock diet show a high degree of protection against experimental ulceration following pyloric ligation. Wheat bran and ragi (a millet) conferred some protection, whereas rice bran and maize conferred no protection. The protection conferred by raw cabbage was destroyed by cooking. The lettuce used conferred no protection. The significance of such findings with regard to the geographical distribution of duodenal ulcer in India and Africa is discussed.
\end{abstract}

\section{Introduction}

In this paper it is shown that the incidence of gastric ulceration in Shay ligated rats depends on the type of diet the rats have had for the preceding fortnight. These experiments arose from observations made about the geographical distribution of duodenal ulcer in rural areas of India and Africa. In these countries the prevalence of duodenal ulceration varies remarkably from area to area in a fashion which suggests that regional factors may contribute to or protect against ulceration. Thus, duodenal ulcer is relatively rare in North India but is common throughout South India and parts of Kashmir and Assam. In Africa duodenal ulcer is rare in Kenya, Zambia, Tanzania (apart from the northern hills), most of Zaire, Malawi, Lesotho, Natal and the Transvaal. There are well localized areas of high incidence along the West Coast, in Ethiopia, Southern Uganda, Rwanda and Burundi (the Nile-Congo watershed) and the northern hill districts of Tanzania around Kilimanjaro. The ulcers in these high incidence areas in India and Africa are often associated with pyloric stenosis, whereas haemorrhage and perforation are rare. In comparison with western countries duodenal ulcer shows a marked male predominance and the peak age incidence is a decade earlier. Gastric ulcer is relatively rare. The evidence

\footnotetext{
* Address for reprints: 'Crossboro', 11 Crossborough Hill, Basingstoke, Hampshire.
}

suggests that local environmental factors, possibly dietary, may be important in the aetiology and characteristics of duodenal ulcer in these countries (Cleave, 1962, 1974; Tovey, 1972, 1974a, 1975).

The work of Cheney $(1940,1948,1949,1950 \mathrm{a}, \mathrm{b}$, c), Singh, Zaidi and Bajpal (1962), Adami (1955, 1964) and Wissmer and Adami (1965) suggested that a factor in the aetiology of peptic ulcer might be the absence of protective substances, either as a result of the refining of the staple carbohydrate food or as a result of an associated low intake of supplementary foods containing such factors. Their experiments on chicks, guinea-pigs and rats, using several different methods of producing experimental ulcers, repeatedly showed that prefeeding with certain foodstuffsegg yolk, milk, butter, green vegetables, lettuce and, in particular, cabbage-would protect the animals against ulceration. The protective factor was thermolabile and was destroyed to a variable extent in different experiments by heating and pasteurization. In the case of cabbage the activity varied according to season, the freshness and the type of cabbage.

The following experiments were undertaken to investigate the effect of prefeeding with foodstuffs on experimental ulceration in the rat, having in mind the diets in high and low incidence areas of India and Africa.

\section{Material and methods}

Female albino rats, weighing $100-160 \mathrm{~g}$, were fed on the required food substances for a period of 2 weeks and then given water only for $24 \mathrm{hr}$. A pyloric ligation (Shay et al., 1945, 1948) was then performed under ether anaesthesia. The stomach was washed out with $4 \mathrm{ml}$ or more of normal saline and then $2 \mathrm{ml}$ normal saline was introduced into the stomach and left there until the rats were killed $6 \mathrm{hr}$ later. The oesophagus was then ligated and the stomach, with contents, was removed. The stomach was then opened and the contents collected. The number of macroscopic ulcers in the rumen and the mucosal part of the stomach were recorded separately, together with 
the number of rats affected. The acidity and pepsin activity of the gastric contents were also estimated. Histological studies were made of the rumen and mucosa of each rat using PAS staining to show mucus secreting cells and Bensley's neutral gentian stain for zymogen granules.

The combinations of food substances investigated were as follows.

\section{Group 1, using rice diet}

(a) Polished rice (cooked) $+2 \%$ salt;

(b) polished rice (cooked) $+2 \%$ salt $+30 \%$ bran;

(c) polished rice (cooked) + supplement;

(d) unmilled rice (cooked) + supplement.

The supplement was made up to resemble what a middle-class South Indian family would take during a day in addition to rice. It was as follows: dhal, 5 parts; brinjal (aubergine), 8 parts; cabbage, 2 parts; peanut oil, 5 parts; salt, 1 part; whole milk powder, 1 part; (rice to 100 parts). The supplement was given fresh and not cooked.

Sixteen rats were included in each sub-group; of these, eight were subjected to pyloric ligation and the stomachs of the other eight were examined without added pyloric ligation. This was because the rice diets were known to be deficient, and deficient diets alone may produce ulcers of the rumen (McCarrison, 1931; Pappenheimer and Larrimore, 1924; Hoelzel and De Costa, 1937). As controls, the stomachs of a further eight rats, on a balanced laboratory stock diet, were examined without pyloric ligation.

The rats on rice alone (polished or unmilled) lost weight-average $10 \mathrm{~g}$ in 2 weeks; those on rice diet plus supplement gained relatively little-average 23 $\mathrm{g}$ in 2 weeks; those on stock diet gained between $\mathbf{4 0}$ and $80 \mathrm{~g}$ in 2 weeks.

\section{Group 2, using laboratory stock diet}

To avoid any difference in results being attributable to inadequate nutrition, further experiments were conducted using stock diet as the basic food. The experiments were designed to determine the protective effect of vegetables (brinjal, cabbage and lettuce) both cooked and uncooked, of unrefined staple carbohydrate or of bran, and of lentils and milk powder.

The stock diet used was 41B made up of Sussex ground oats $40 \%$, wholemeal flour $46 \%$, white fish meal $8 \%$, dried yeast $1 \%$, dried skimmed milk $3 \%$, mineral supplement $1 \%$ and vitamin supplement $1 \%$.

Eight or more rats were allocated to each subgroup as shown below, all of which underwent pyloric ligation.

(a) Stock diet alone;

(b) stock diet + raw brinjal $8 \%+$ cabbage $2 \%$ (spring, long leafed); (c) stock diet + raw brinjal $10 \%$;

(d) stock diet + raw cabbage $10 \%$ (spring, long leafed);

(e) stock diet + raw cabbage $10 \%$ (autumn, ball cabbage);

(f) stock diet + cooked cabbage $10 \%$ (autumn, ball cabbage);

(g) stock diet + raw lettuce $10 \%$ (long leafed variety);

(h) stock diet + cooked lettuce $10 \%$ (long leafed variety);

(i) stock diet + wheat bran $20 \%$;

(j) stock diet + rice bran $20 \%$;

(k) stock diet + ragi $15 \%$;

(l) stock diet + maize $20 \%$;

(m) stock diet + cooked dhal 5\%;

(n) stock diet + skimmed milk powder $3 \%$.

\section{Results}

Table 1 has been constructed to show the number of macroscopic ulcers in the rumen and in the mucosal part of the stomachs together with the number of rats affected.

Figures $1,2 \mathrm{a}$ and $2 \mathrm{~b}$ show the 'mean ulcer score'. This was calculated by dividing the number of macroscopic ulcers recorded by the number of rats in each dietary group.

\section{Macroscopic changes}

In the series of thirty-two rats on rice diets without pyloric ligation, only two of the rats in the polished rice group showed ulcers of the rumen (mean ulcer score $=0.05$ ). The eight sacrificed after 2 weeks on stock diet without pyloric ligation had no rumenal ulcers. There were no mucosal ulcers in any group. Thus malnutrition alone from a deficient rice diet, if given for only 2 weeks, was not a potent cause of rumenal ulceration.

The results of the pyloric ligation series are discussed below.

\section{(a) Numbers of ulcers produced}

Rice diets. There were no mucosal ulcers in this group (Table 1 and Fig. 1), but the frequency of rumenal ulcers was high in those fed with polished rice and polished rice and bran. Six of the eight rats with polished rice and three of the eight with polished rice plus bran developed ulcers. Almost $33 \%$ of the ulcers were large and it might be considered that this diet either predisposed the rats to ulceration or at least offered them no protection (using the results of ulceration from the pyloric ligated group fed on stock diet alone as a control, however, there is no significant difference, using the chi-squared test, either in the number of ulcers, the number of rats affected, or the frequency of large ulcers. The only real difference is that mucosal ulcers 
TABLE 1. Incidence of mucosal and rumenal ulcers

\begin{tabular}{|c|c|c|c|c|c|c|c|}
\hline & \multirow[b]{2}{*}{$\begin{array}{l}\text { No. of } \\
\text { rats }\end{array}$} & \multicolumn{2}{|c|}{ Mucosal ulcers } & \multicolumn{4}{|c|}{ Rumenal ulcers } \\
\hline & & $\begin{array}{l}\text { No. of rats } \\
\text { with ulcers }\end{array}$ & $\begin{array}{l}\text { Total no. } \\
\text { of ulcers }\end{array}$ & $\begin{array}{l}\text { No. of rats } \\
\text { with ulcers }\end{array}$ & $\begin{array}{l}\text { Total no. } \\
\text { of ulcers }\end{array}$ & $\begin{array}{l}\text { Large } \\
\text { ulcers }\end{array}$ & Perforations \\
\hline \multicolumn{8}{|l|}{ Rice diets } \\
\hline Polished rice & 8 & 0 & $\mathbf{0}$ & 6 & 25 & 10 & 0 \\
\hline Polished rice + bran & 8 & 0 & $\mathbf{0}$ & 3 & 30 & 11 & 0 \\
\hline Polished rice + supplement & 8 & 0 & 0 & 0 & 0 & 0 & 0 \\
\hline Unrefined rice + supplement & 8 & 0 & 0 & 0 & 0 & 0 & 0 \\
\hline \multicolumn{8}{|l|}{ Stock diets } \\
\hline $\begin{array}{l}\text { (a) Stock diet alone } \\
\text { (b) Stock diet plus vegetables }\end{array}$ & 16 & 7 & 15 & 9 & 40 & 20 & 0 \\
\hline + cooked lettuce & 8 & 2 & 12 & 6 & 77 & 6 & 0 \\
\hline + raw lettuce & 8 & 0 & 0 & 7 & 70 & 9 & 0 \\
\hline+ cooked autumn cabbage & 6 & 1 & 4 & 4 & 9 & $\mathbf{0}$ & 0 \\
\hline + raw autumn cabbage & 8 & 0 & $\mathbf{0}$ & 3 & 4 & 0 & 0 \\
\hline + brinjal & 7 & 1 & 1 & 2 & 3 & 1 & $\mathbf{0}$ \\
\hline + raw spring cabbage & 8 & 0 & 0 & 2 & 2 & 0 & $\mathbf{0}$ \\
\hline $\begin{array}{l}+ \text { brinjal and raw spring cabbage } \\
\text { (c) Stock diet plus unrefined foods, etc. }\end{array}$ & 8 & $\mathbf{0}$ & 0 & 0 & 0 & 0 & 0 \\
\hline+ maize & 7 & 2 & 5 & 4 & 25 & 12 & 2 \\
\hline + rice bran & 8 & 4 & 8 & 8 & 23 & 0 & 3 \\
\hline+ ragi & 8 & 0 & 0 & 6 & 21 & 8 & 2 \\
\hline+ wheat bran & 9 & 0 & 0 & 4 & 30 & 0 & 1 \\
\hline + cooked dhal & 8 & 0 & 0 & 3 & 8 & 0 & 0 \\
\hline+ milk powder & 8 & 0 & 0 & 2 & 2 & 0 & 0 \\
\hline
\end{tabular}

Mucosa

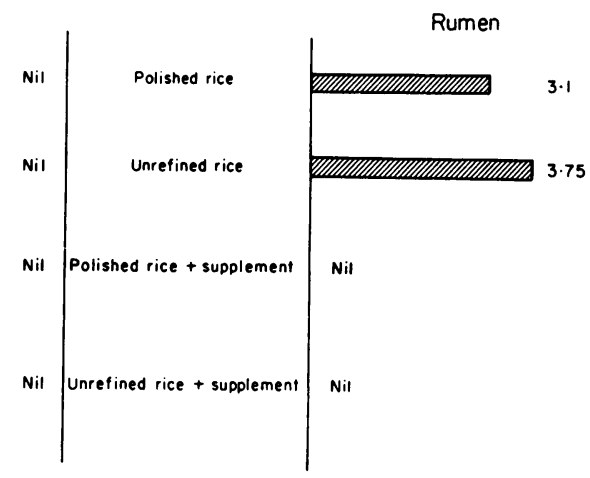

FIG. 1. Mean ulcer scores-rice diets.

as well as rumenal ulcers occurred in the stock diet group).

The addition of supplement to either polished or unmilled rice reduce the incidence of ulceration to nil, thus suggesting that these substances offer a protective effect. This was further investigated by examining the individual components of supplement added to stock diet.

Stock diet. Table 1 and Fig. 2a show the results when green vegetables (lettuce, cabbage, brinjal) are added to stock diet, and Table 1 and Fig. $2 b$ when bran, other unrefined carbohydrates (maize, ragi), dhal or milk are similarly added. The results show a general trend in that mucosal ulcers usually exist when the incidence of rumenal ulcer is high, although the results for raw lettuce added to stock diet are an exception. Since the factors influencing mucosal ulceration may differ from those producing rumenal ulceration it may be better to examine them separately.

The effect of vegetables (Table 1 and Fig. 2a). (1) Lettuce. There is a highly significant difference in the number of rumenal ulcers found with the addition of raw or cooked lettuce $(P=0.01$, using the chi-squared test) but comparison of the number of rats affected shows a significant increase only in respect of the group with added raw lettuce $(P=$ $0 \cdot 01)$ and fails to reach significance with cooked lettuce. Whether or not lettuce contains a potential ulcerogenic factor remains to be determined but, if so, from the mean ulcer score, it is a factor less evident with raw lettuce rather than cooked lettuce. Furthermore, only with cooked lettuce is there ulceration of the mucosa, although this does not differ from the frequency with stock diet alone.

(2) Cabbage. The results for cooked cabbage added to stock diet show a lower incidence of rumenal ulceration compared with stock diet alone, but the difference is not statistically significant. Nor is there any difference in the incidence of mucosal ulceration. However the addition of raw cabbage, either spring or autumn varieties, results in a significant reduction in the incidence of rumenal ulceration $(P=0.02)$ and complete absence of mucosal ulceration.

(3) Brinjal. The addition of brinjal results in a 


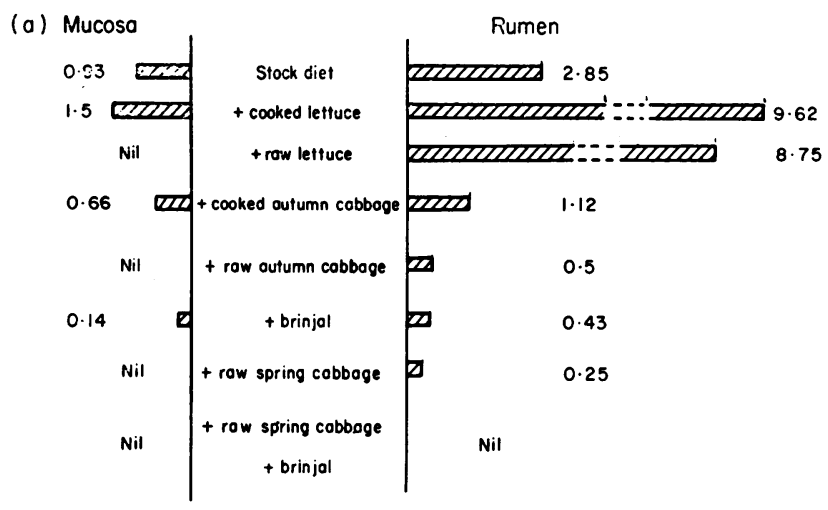

(b) Mucosa

Rumen

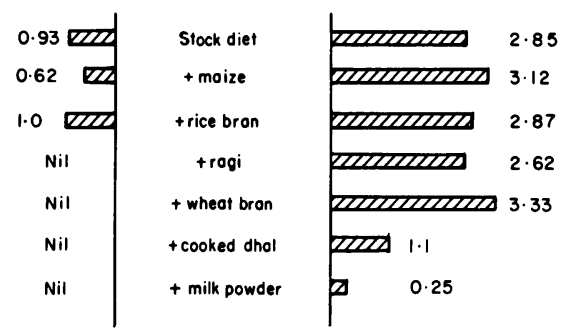

FIG. 2. Mean ulcer scores, (a) stock diet plus vegetables; (b) stock diet plus unrefined grains etc. Mean ulcer score $=\frac{\text { no. of ulcers }}{\text { no. of rats }}$ in each group.

significant reduction of rumenal ulceration and mucosal ulceration $(P=0.02$ and $P=0.01)$.

(4) Brinjal and cabbage. The combination of brinjal and raw spring cabbage seems to offer com. plete protection against ulceration.

The effect of unrefined foods, etc. (Table 1 and Fig. 3). Of the other additives to stock diet, only milk powder shows a significant reduction in rumenal ulceration, although cooked dhal, wheat bran and ragi appear to protect against mucosal ulceration.

Conclusion. Of the compounds included in the rice supplement, i.e. dhal, brinjal, cabbage and whole milk, all except dhal show a protective effect in respect of rumenal ulceration and all, including dhal, appear to protect the mucosa from ulceration.

\section{(b) Size of ulcers}

The size of ulcers seen in the rumen may have some importance and twenty large ulcers were found in the control group on stock diet. In the treated groups large ulcers occurred with similar frequency with added raw lettuce, cooked lettuce, maize and ragi. None of these substances had any significant effect on the number of rumenal ulcers apart from raw lettuce which appeared to increase the ulcerogenic potential. One large ulcer occurred with brinjal which in other respects appeared to offer protection from ulceration.

\section{(c) Presence of perforations}

Perforation of ulcers occurred in four groupsmaize, wheat bran, rice bran and ragi. Ragi and wheat bran appeared to offer protection against mucosal ulceration but none of these four additions influenced rumenal ulceration.

\section{Microscopic changes, acid and pepsin secretion}

The stomachs were examined histologically for erosions, congestion and inflammatory cell infiltration of the mucosa and of the epithelium of the rumen. The changes corresponded with the macroscopical appearance. Erosions of the rumen were accompanied by epithelial thickening and keratinization.

The rats with a high ulcer score showed a marked increase in zymogen granules in the peptic cells of the 
TABLE 2. Acid and pepsin concentrations arranged in order of rumenal ulcer scores

\begin{tabular}{|c|c|c|c|c|}
\hline & $\begin{array}{l}\text { No. of } \\
\text { samples }\end{array}$ & $\begin{array}{l}\text { Rumenal } \\
\text { ulcer score }\end{array}$ & $\begin{array}{c}\text { Acid } \\
(\mathrm{mEq} \mathrm{HCl} / \mathrm{l}) \\
\text { Mean + s.d. }\end{array}$ & $\begin{array}{c}\text { Pepsin } \\
(\mathrm{u} / \mathrm{ml}) \\
\text { Mean + s.d. }\end{array}$ \\
\hline \multicolumn{5}{|l|}{ (a) Rice diets } \\
\hline Polished rice & 8 & $3 \cdot 1$ & $61 \pm 13$ & $53 \pm 7 \cdot 2\}_{P}$ \\
\hline Polished rice + supplement & 7 & 0 & $65 \pm 23$ & $30 \cdot 6 \pm 6 \cdot 1\}$ \\
\hline Polished rice + bran & 6 & $3 \cdot 75$ & $54 \pm 12$ & $34 \pm 3 \cdot 8\}$ \\
\hline Unrefined rice + supplement & 7 & 0 & $41 \pm 27$ & $24 \cdot 4 \pm 5 \cdot 4\}$ \\
\hline \multicolumn{5}{|l|}{ (b) Stock diets } \\
\hline Stock diet & 15 & $2 \cdot 85$ & $49 \cdot 6 \pm 10 \cdot 7$ & $41 \cdot 4 \pm 8 \cdot 8$ \\
\hline + cooked lettuce & 8 & $9 \cdot 62$ & $45 \cdot 6 \pm 16 \cdot 7$ & $36 \cdot 3 \pm 7 \cdot 0$ \\
\hline + raw lettuce & 8 & $8 \cdot 75$ & $40 \cdot 0 \pm 18 \cdot 0$ & $34 \cdot 7 \pm 5 \cdot 9$ \\
\hline + wheat bran & 7 & $3 \cdot 33$ & $59 \cdot 5 \pm 16 \cdot 0$ & $38 \cdot 3 \pm 1 \cdot 8$ \\
\hline+ maize & 7 & $3 \cdot 12$ & $38 \cdot 1 \pm 15 \cdot 1$ & $28 \cdot 3 \pm 5 \cdot 6^{*}$ \\
\hline + rice bran & 6 & $2 \cdot 87$ & $49 \cdot 0 \pm 9 \cdot 8$ & $39 \cdot 9 \pm 3 \cdot 4$ \\
\hline + ragi & 5 & $2 \cdot 62$ & $61 \cdot 6 \pm 9 \cdot 3$ & $34 \cdot 1 \pm 2 \cdot 2$ \\
\hline + cooked autumn cabbage & 7 & $1 \cdot 12$ & $56 \cdot 0 \pm 13 \cdot 4$ & $39 \cdot 0 \pm 3 \cdot 3$ \\
\hline+ cooked dhal & 8 & $1 \cdot 10$ & $50 \cdot 6 \pm 15 \cdot 0$ & $38 \cdot 0 \pm 6 \cdot 9$ \\
\hline + raw autumn cabbage & 8 & $0 \cdot 50$ & $64 \cdot 6+12 \cdot 8$ & $42 \cdot 7 \pm 7 \cdot 7$ \\
\hline + brinjal & 7 & 0.43 & $71 \cdot 0 \pm 15 \cdot 9$ & $29 \cdot 6 \pm 3 \cdot 1^{*}$ \\
\hline+ milk powder & 8 & 0.25 & $45 \cdot 7 \pm 11 \cdot 1$ & $32 \cdot 8 \pm 6 \cdot 1$ \\
\hline + raw spring cabbage & 8 & $0 \cdot 25$ & $58 \cdot 0 \pm 16 \cdot 6$ & $37 \cdot 2 \pm 2 \cdot 9$ \\
\hline + brinjal and raw spring cabbage & 8 & 0.00 & $56 \cdot 5 \pm 10 \cdot 8$ & $22 \cdot 5 \pm 2 \cdot 5^{*}$ \\
\hline
\end{tabular}

(* = Fall in pepsin concentration significant to $P<0.001$ ). Acid titrations to pH 7.0 with $\mathrm{N} / 100 \mathrm{NaOH}$.

Pepsin estimations using method of Anson and Mirsky with human plasma as a substrate (Sen and Roy, 1963).

mucosa and a scanty amount of mucus in the mucussecreting cells. Conversely, those with a low ulcer score showed a more intense PAS staining for mucus and very little staining for zymogen.

The degrease in mucus in the rats showing ulceration is consistent with a reduced mucosal resistance, but the significance of the difference in zymogen granules is not clear. The increase in zymogen granules in the cells was not accompanied by a fall in pepsin concentration in the gastric secretion as might have been expected. No significant relationship could be found between the ulcer score and the acid or pepsin concentrations of the gastric contents (Table 2a, b), except that the addition of supplement in the rice group was accompanied by a significant fall in pepsin concentration with both polished and unrefined rice $(P<0.001$ and $<0.005$ respectively, using Student's $t$ test). Likewise, in the stock diet group, the pepsin concentration showed a significant fall when brinjal + raw spring cabbage were added $(P<0.001)$. All the above groups also had low or nil ulcer scores. A significant fall in pepsin concentration also occurred with added maize $(P<0.001)$ with no fall in ulcer score.

\section{Discussion}

Pyloric ligation is an accepted method of studying peptice ulceration in an animal model. It is a form of acute stress ulceration, suitable for examining the potential therapeutic effects of drugs, or, in the present case, the ulcerogenic potential or protective effect of prefeeding with certain food substances.

Normally pyloric ligation results in ulcers of the rumen only but, in these experiments, mucosal ulceration also occurred. From the point of view of relating these results to the aetiology of peptic ulcer, the occurrence of mucosal ulceration may be more important than rumenal ulceration, although it can be seen that it tends to occur in circumstances where the rumenal ulcer score is high.

The results of these experiments showed that rice bran when added to a rice diet had no protective action against experimental ulceration but that a supplement of uncooked brinjal, cabbage, dhal, peanut oil and milk powder gave complete protection. Raw cabbage, brinjal and milk powder also conferred almost complete protection to rats on a stock diet. When added to stock diet, wheat bran and ragi (millet) provided some protection against mucosal but not against rumenal ulceration, whereas rice bran and maize gave no protection at all. Cooking autumn cabbage impaired the protective action causing an increase in rumenal ulcer score from 0.5 to 1.2 and mucosal ulcer score from 0 to $0 \cdot 66$. Lettuce gave no protection in this series. In these experiments any protective effect was a result of prefeeding. This suggests that the unknown protective factor must have a systemic effect acting on gastric mucosa in a similar way to drugs such as carbenoxolone.

The findings suggest that such protective factors 
are more likely to be found in certain fresh green vegetables or lentils rather than in bran or unrefined staple carbohydrate foods. This may have some bearing on the geographical distribution of duodenal ulcer (Tovey, 1974a; Cleave, 1962, 1974).

Burkitt and Tovey (Tovey, 1974b) have collected information from India and Africa in search of distinctive dietary differences between high and low incidence areas of duodenal ulceration. The picture is confusing. In North India, where duodenal ulcer is rare, the diet is often supplemented by milk, fresh radishes and green vegetables. In South India, where duodenal ulcer is common, the diet may be supplemented by small amounts of vegetables and pulses similar to the combination used in the rice diet experiments above, but these are subjected to prolonged cooking, making it probable that any thermolabile protective factor would be destroyed. The dietary patterns obtained from Africa, however, do not at present support any suggestion that fresh green vegetables or pulses are consumed more in low incidence than in high incidence areas. Along the West Coast, indeed, the evidence seems to be to the contrary, in that duodenal ulcer is commoner in the coastal area where green vegetables and leaves are more available than in the drier savannah areas to the north where they are less available, although perhaps the shortage of fuel in the drier areas may result in less cooking. The overall evidence does not suggest that the quantitative consumption of fresh green vegetables is likely to prove to be more than a minor aetiological factor. The experimental evidence, however, showed that the protective effect varies from vegetable to vegetable and from season to season, and this needs more detailed investigation.

The geographical distribution of duodenal ulcer does, however, seem to have a definite relationship to the consumption of unrefined or refined staple carbohydrate foods as distinct from green vegetables or other supplements. Thus, in North India the staple diet is unrefined wheat in the form of chapattis, and in South India and the high incidence areas of Kashmir and Assam the staple diet is refined milled rice (plus cassava in certain areas).

In the low incidence areas of Africa already mentioned the staple diet is unrefined maize, except in the northern savannah areas of the West Coast, where it is millet. In the high incidence coastal areas of the West Coast the staple carbohydrate diet tends to be either milled or in some way refined in its processing-yam, cassava, rice, wheat. This all suggests that the refinement of staple carbohydrate food may have some relationship to the incidence of duodenal ulceration. There are, however, exceptions which do not fit into this pattern. In the Nile-Congo watershed (Rwanda and Burundi), apart from seasonal cassava, the staple diet is of millets, beans and peas. In the high incidence areas around Kilimanjaro the main carbohydrate is unrefined maize and in the high incidence areas of Ethiopia it is millet (teff).

Apart from these exceptions the overall evidence favours the concept that unrefined staple carbohydrates may offer some protection. The above prefeeding experiments however suggest that if such protection is present in unrefined staple carbohydrates apart from added vegetable or other supplements, it is not due to a protective factor with a systemic effect analogous to carbenoxolone increasing the intrinsic resistance of the mucosa to ulcerogenic factors. It is still possible that such foods may have a direct effect on acid or pepsin.

Cleave $(1962,1974)$ suggested that considerable loss of buffer, particularly in the form of protein, could result from the refining processes of the methods of preparation of certain staple carbohydrate foods. The experimental evidence is again confusing. Lennard-Jones, Fletcher and Shaw (1968) showed that refined carbohydrates produced lower intragastric pH levels than unrefined carbohydrates. Tovey (1974b) found that wheat and rice bran and certain unrefined grains had a significant buffering effect in vitro, but that in vivo this was offset by their stimulatory effect on the gastric antrum resulting in higher acid outputs. It was also shown that unrefined carbohydrates or bran had no inhibitory effect on pepsin activity.

Much of the emphasis of dietary surveys conducted up to date has been on the identification of factors which act directly on the mucosa, thereby either increasing or reducing its resistance to ulceration or affecting its secretion of acid and pepsin. Another important aspect has been concerned with the buffering or antipepsin effect of food. The above work suggests that it is also important to be looking for protective factors which act systemically and not directly on the mucosa increasing its resistance to ulceration. The information available at present suggests that a complex pattern involving all three may be involved in accounting for the marked variations in the geographical distribution of duodenal ulcer.

\section{Acknowledgment}

The authors are grateful to Mr D. Stoker and Mr Parikh of Crooke's Laboratories, Basingstoke, for their great help with the acid and pepsin estimations.

\section{References}

Adami, E. (1955) Experimental studies on the anti-ulcer factor. Atti della Società lombarda di scienze mediche $e$ biologiche, 10, 60.

ADAMI, E. (1964) A new class of drugs active in gastroduodenal ulcers. Clinica Europa, 3 (Typescript only available). 
Cheney, G. (1940) Effect of diet and cinchophen on production of experimental gastric ulcers in chicks. Proceedings of the Society for Experimental Biology and Medicine, 45, 190

Cheney, G. (1948) Prevention of histamine-induced peptic ulcers by diet. Stanford Medical Bulletin, 6, 334.

CHENEY, G. (1949) Rapid healing of peptic ulcers in patients receiving fresh cabbage juice. California Medicine, $\mathbf{7 0}, 10$.

Cheney, G. (1950a) Anti-peptic ulcer dietary factor. Journal of the American Dietetic Association, 26, 668.

Cheney, G. (1950b) Vitamin U therapy of peptic ulcer. California Medicine, 77, 248.

Cheney, G. (1950c) The nature of the anti-peptic ulcer dietary factor. Stanford Medical Bulletin, 8, 144.

Cleave, T.L. (1962) Peptic Ulceration. John Wright and Sons, Bristol.

Cleave, T.L. (1962) The Saccharine Disease. John Wright and Sons, Bristol.

Hoelzel, F. \& de Costa, E. (1937) Production of peptic ulcers in rats and mice by diets deficient in protein. American Journal of Digestive Diseases, 4, 325.

Lennard-Jones, J., Fletcher, J. \& SHAW, D.G. (1968) Effect of different foods on the acidity of the gastric contents in patients with duodenal ulcer. Gut, 9, 177.

MCCARRISON, R. (1931) Experimental production of gastric ulcer in albino rats. Indian Journal of Medical Research, 19, 61 .

Pappenheimer, A.M. \& Larrimore, L.D. (1924) The occurrence of gastric lesions in rats. Journal of Experimental Medicine, 40, 719.
SEN, S.B. \& Roy, N.K. (1963) Studies in pepsin secretion in healthy subjects and ulcer patients. Indian Journal of Medical Research, 51, 23.

Shay, H., Komarov, S.A., Fels, S.S., Meranzo, D., Gruenstein, M. \& Siplet, H. (1945) A simple method for the uniform production of gastric ulceration in the rat. Gastroenterology, 5, 43.

Shay, H., Gruenstein, M., Siplet, H. \& Komarov, S.A. (1948) Protection of the gastric mucosa of the rat against ulceration by pre-feeding with protein hydrolysate. Proceedings of the Society for Experimental Biology and Medicine, 69, 369.

Singh, G.B., Zaidi, S.H. \& BaJPal, R.P. (1962) Effect of Brassica oleracea in the prevention and healing of experimental peptic ulceration. Indian Journal of Medical Research, 50, 741.

TOVEY, F.I. (1972) Duodenal ulcer in Mysore. Tropical and Geographical Medicine, 24, 107.

Tovey, F.I. (1974a) Geographical distribution of peptic ulcer. Tropical Doctor, 4, 17.

TOVEY, F.I. (1974b) An investigation into the buffering action and the effect on pepsin of bran and unrefined carbohydrate foods. Postgraduate Medical Journal, 50, 683.

ToveY, F.I. (1975) Peptic ulcer. In: Refined Carbohydrate Foods and Disease (Ed. by D. Burkitt and H. Trowell). London, Academic Press Inc. (awaiting publication).

Wissmer, B.A.L. \& AdAmi, E. (1965) A new way in ulcer therapy? Current Therapeutic Research, 7, 474. 